ESPAÇO IMAGEM

IMAGING SPACE

Responsável: Manoel Barros Bértolo

\title{
Esclerodermia com Múltiplas Calcinoses
}

\section{scleroderma with Multiple Calcinosis}

Figura 1

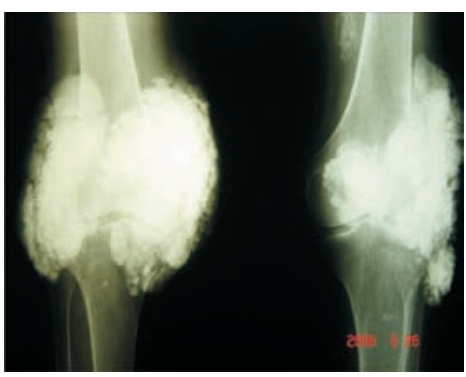

Figura 2

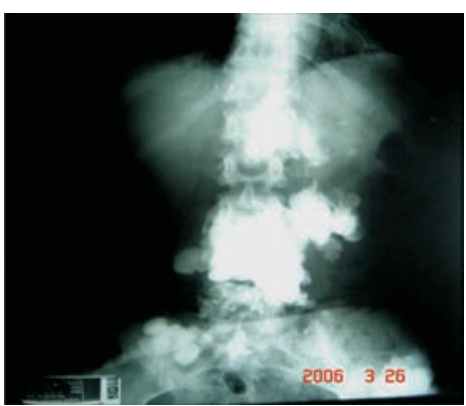

Figura 3

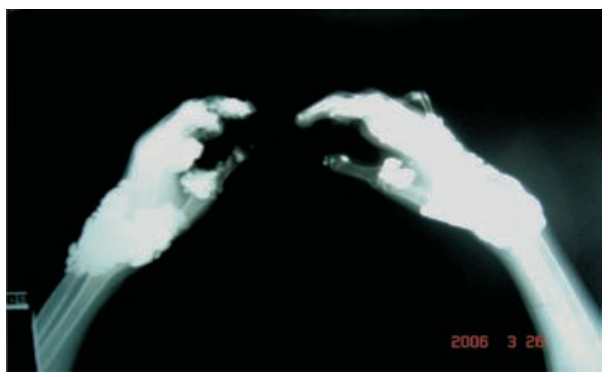

Figura 4

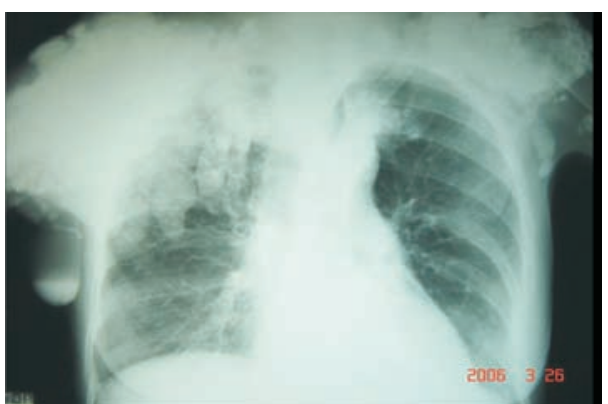

Sexo feminino, 55 anos, com diagnóstico de esclerodermia do tipo CREST (calcinose, fenômeno de Raynaud, dismotilidade esofageana, esclerodactilia e telangiectasia) desde 1992, com FAN positivo (padrão homogêneo), em uso de D-penicilamina, $250 \mathrm{mg} /$ dia, e prednisona, $5 \mathrm{mg} / \mathrm{dia}$. Apresenta calcinoses difusas como podem ser observadas nas radiografias. Figura 1: Radiografia de joelhos; Figura 2: Radiografia de coluna lombar; Figura 3: Radiografia de mãos e punhos; Figura 4: Radiografia de tórax.

Caso encaminhado por Marcos Antônio Leão de Araújo, Mayara de Oliveira Mafra, Ênio Ricardo Vasconcelos Souza, médicos-residentes; Sandra Lúcia Euzébio Ribeiro, médica preceptora do Serviço de Reumatologia da Universidade Federal do Amazonas (UFAM), Manaus, AM, Brasil. E-mail: sandraeuzebio@vivax.com.br 